\title{
Observed to expected 30-day mortality as a benchmark for transcatheter aortic valve replacement
}

Matthew C. Henn, MD, ${ }^{a}$ Alan Zajarias, MD, ${ }^{b}$ Nishath Quader, MD, ${ }^{b}$ Marc Sintek, MD, ${ }^{b}$

John M. Lasala, MD, ${ }^{b}$ Kelly Koogler, MCH, ${ }^{a}$ Marci S. Damiano, RN, MSN, ${ }^{b}$ Puja Kachroo, MD,

D. Craig Miller, MD, ${ }^{c}$ C. Ryan King, MD, PhD, ${ }^{\mathrm{d}}$ Spencer J. Melby, MD, ${ }^{\mathrm{a}}$ Marc R. Moon, MD, ${ }^{\mathrm{a}}$

Ralph J. Damiano, Jr, MD, ${ }^{a}$ and Hersh S. Maniar, MD $^{\mathrm{a}}$

\section{ABSTRACT}

Objective: The observed-to-expected 30-day mortality ratio (O:E ratio) is a standard metric by which transcatheter aortic valve replacement (TAVR) trials have been evaluated. Early TAVR trials consistently demonstrated O:E ratio less than 0.6 after TAVR when based on the Society for Thoracic Surgery Predicted Risk of Mortality (STS-PROM) for surgical aortic valve replacement. Recent published results from the Transcatheter Valve Therapy (TVT) Registry have demonstrated O:E ratios of 1.0. We evaluated our own O:E ratios for TAVR to investigate this discordance.

Methods: Data were collected prospectively for TAVR patients from 2008 through $2015(\mathrm{~N}=546)$ and were reviewed retrospectively. The observed mortality and STS-PROM were calculated to formulate O:E ratios and were compared over a variety of subgroups.

Results: Overall, the O:E ratio for 30-day mortality was 0.4 and significantly less than $1(P<.001 ; 95 \%$ confidence interval, $0.25-0.63)$. The O:E ratio relationship remained less than 0.5 for patients with low (STS-PROM $<4$ ), moderate (STSPROM $=4-8$ ) and high risk (STS-PROM $>8$ ). The O:E ratio was significantly higher for transapical patients $(\mathrm{O}: \mathrm{E}$ ratio $=0.8)$ when compared with transfemoral patients (O:E ratio $=0.2$ ). Lastly, O:E ratios for both commercial (O:E ratio $=0.5)$ and research $(\mathrm{O}: \mathrm{E}$ ratio $=0.3)$ patients were similar $(P=.337)$, and both were significantly less than $1(P=.007$ and $P<.001$, respectively).

Conclusions: The STS-PROM consistently overestimated 30-day mortality after TAVR. Achieving an O:E ratio less than 0.6 may be a realistic goal for all TAVR programs. While an accurate and specific risk calculator for 30-day mortality after TAVR remains to be established, our data suggest that current TVT results are not acceptable for commercial TAVR and that programs with an O:E ratio greater than 0.6 , based on the STS-PROM, should reevaluate internal processes to improve their results. (J Thorac Cardiovasc Surg 2019;157:874-82)

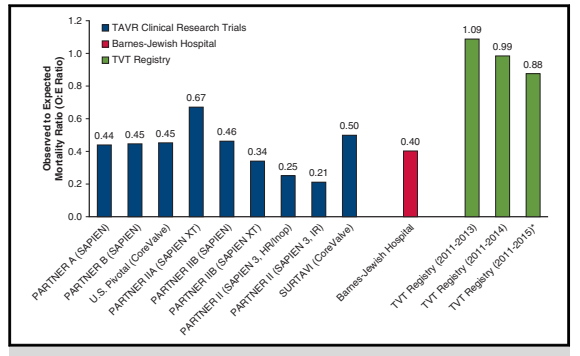

Observed to expected mortality ratios are compared between the TAVR trials, the current study, and the TVT registry.

\section{Central Message}

Thirty-day TAVR results from this study are superior to the TVT registry, suggesting that some programs are offering TAVR without the mortality benefit associated with this less invasive procedure.

\section{Perspective}

Our data and those from early TAVR trials suggest that an O:E ratio less than 0.6 is a reasonable benchmark for 30-day mortality. Nationally, commercial TAVR is associated with higher 30-day mortality, suggesting that some programs may be offering TAVR without the benefit associated with this less invasive procedure.

See Commentaries on pages 883 and 884.
From the a Division of Cardiothoracic Surgery, Department of Surgery, ${ }^{\mathrm{b}}$ Cardiovascular Division, Department of Medicine, and ${ }^{\mathrm{d}}$ Department of Anesthesiology, Washington University School of Medicine, Barnes-Jewish Hospital, St. Louis, Mo; and ${ }^{c}$ Department of Cardiovascular Surgery, Stanford University Medical School, Falk CV Research Center, Stanford, Calif.

Read at the 97th Annual Meeting of The American Association for Thoracic Surgery, Boston, Massachusetts, April 29-May 3, 2017.

Received for publication May 25, 2017; revisions received June 8, 2018; accepted for publication June 27, 2018; available ahead of print Nov 16, 2018.

Address for reprints: Hersh S. Maniar, MD, Division of Cardiothoracic Surgery, Washington University School of Medicine, 660 S. Euclid Ave, Campus Box 8234, St. Louis, MO 63110 (E-mail: maniarh@wudosis.wustl.edu). $0022-5223 / \$ 36.00$

Copyright $₫ 2018$ Published by Elsevier Inc. on behalf of The American Association for Thoracic Surgery

https://doi.org/10.1016/j.jtcvs.2018.06.097
The Society for Thoracic Surgery Predicted Risk of Mortality (STS-PROM) score is the most widely used system for estimating risk for surgical aortic valve replacement (SAVR). ${ }^{1}$ Since the introduction of transcatheter aortic

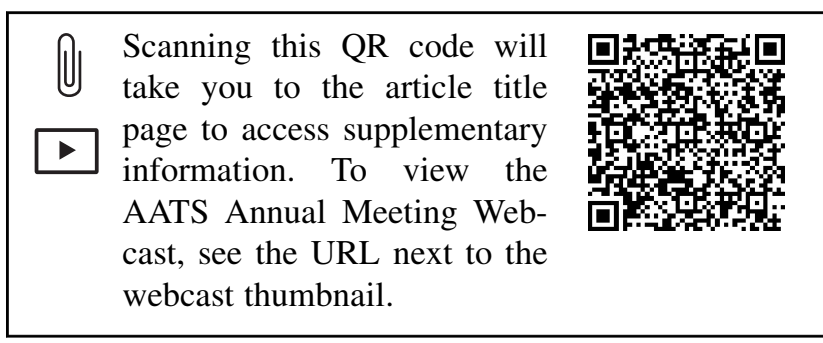




$$
\begin{aligned}
& \text { Abbreviations and Acronyms } \\
& \text { CI = confidence interval } \\
& \text { GLM = generalized linear model } \\
& \mathrm{O}: \mathrm{E} \text { ratio }=\text { Observed-to-expected 30-day } \\
& \text { mortality ratio } \\
& \text { SAVR = surgical aortic valve replacement } \\
& \text { STS = Society for Thoracic Surgery } \\
& \text { STS-PROM }=\text { Society for Thoracic Surgery } \\
& \text { Predicted Risk of Mortality } \\
& \text { TA } \quad=\text { transapical } \\
& \text { TAo }=\text { transaortic } \\
& \text { TAVR }=\text { Transcatheter aortic valve } \\
& \text { replacement } \\
& \mathrm{TF}=\text { transfemoral } \\
& \text { TVT }=\text { Transcatheter valve therapy }
\end{aligned}
$$

valve replacement (TAVR) in the United States, ${ }^{2}$ STS-PROM risk scores for SAVR have also been used as a screening tool for patients being considered for TAVR, as seen in the recently published, randomized trials that established TAVR. ${ }^{3-5}$ Despite several modifications over time, the STS-PROM has remained a cornerstone in the subsequent systematic evaluation of TAVR in the United States. Since the U.S. Food and Drug Administration approval for TAVR in 2011, there has been a steady expansion of the indications for TAVR, with the most recent approval in August 2016 to include those with intermediate risk for SAVR defined as STS-PROM risk greater than 3\%.,

Although early TAVR trials and the current indications for TAVR are based primarily on the STS-PROM, the ability of the STS-PROM to predict mortality following TAVR is less well understood. ${ }^{8}$ A common methodology by which to measure outcomes after TAVR is the observed-to-expected 30-day mortality ratio (O:E ratio), calculated by dividing the observed 30-day mortality after TAVR by the expected 30-day mortality as estimated by the STS-PROM for SAVR. ${ }^{9-11}$ The initial large, randomized trials for TAVR all demonstrated a significant survival benefit for TAVR at 30 days when compared with expected mortality, with calculated O:E ratios of 0.4 to 0.6 (Figure 1). ${ }^{3-5,12-16}$

These early research trails suggest that the STS-PROM systematically overestimates the risk of mortality after TAVR; however, recent data from the STS-American College of Cardiology Transcatheter Valve Therapy (TVT) Registry have reported higher observed mortalities since the commercialization of TAVR with O:E ratios approaching or exceeding 1.0 (Table E1, Figure 1). ${ }^{17-21}$ Potential causes for this discrepancy are variations in patient selection, operator experience, STS-PROM version, and the Hawthorne effect, in which studied outcomes are superior to unstudied outcomes. As an experienced, large-volume center that participated in early TAVR trials, we sought to explore these theories by evaluating our own TAVR dataset and comparing O:E ratios in various subgroups over time.

\section{METHODS \\ Patient Population}

This study was approved by the Washington University School of Medicine Institutional Review Board. Written informed consent was obtained from each patient before enrollment. More than 400 demographic and perioperative variables were entered prospectively into a longitudinal database. From 2008 to 2015, a total of 546 patients underwent TAVR at our institution for severe, symptomatic aortic stenosis, and patients with incomplete data were excluded $(n=26)$. Prospectively obtained perioperative data were reviewed retrospectively to answer this research question.

\section{Calculation of $\mathrm{O}: \mathrm{E}$ ratio}

STS-PROM 30-day mortality risk scores were calculated for all patients undergoing TAVR using the STS-PROM risk calculator for SAVR. ${ }^{22}$ The expected risk calculation was based on the most current version of the STSPROM at the time of the procedure (version 2.61 from 2008 to mid-2011, version 2.73 from mid-2011 to mid-2014, and version 2.81 from mid-2014 to 2015$).^{23}$ The STS-PROM defines the 30-day risk of mortality as including all deaths occurring during the hospitalization in which the operation was performed, and those deaths occurring after discharge from the hospital, but within 30 days of the procedure. ${ }^{1}$ Observed 30-day mortality was divided by average expected mortality based on the STS-PROM to obtain O:E ratios, which were then compared across multiple patient groups. Patients were stratified by year of implant, their surgical risk (low, moderate, high), by surgical approach (transfemoral [TF], transaortic [TAo], and transapical [TA]), and by whether the TAVR procedure was conducted as part of a research trial or as a commercial implant. In addition to between-group comparisons, O:E ratios were additionally compared against a reference value of 1 .

To compare previous versions of STS-PROM to the current STS-PROM version 2.81 , we randomly selected 100 patients with STS-PROM scores calculated from earlier versions STS-PROM (versions 2.61 or 2.73). Their STS-PROM scores were recalculated with the current version of STS-PROM (version 2.81), and the average recalculated STS-PROM (version 2.81) was compared to the average original score.

\section{Statistical Analysis}

Continuous variables were expressed as mean $\pm \mathrm{SD}$ or as median with range. Categorical variables were expressed as frequencies and percentages with outcomes compared using the chi-squared test or Fisher exact test when feasible. Continuous outcomes were compared using Student $t$ test for means of normally distributed continuous variables and the Mann-Whitney $U$ nonparametric test for skewed distributions using SYSTAT 13 (Systat Software, Chicago, Ill).

Detailed statistical methodology and reasoning are in the statistical appendix. Confidence intervals and $P$ values for O:E ratios were generated by binomial probability intervals implemented using "binom.test" in $\mathrm{R}$ version 3.4.0 ( $\mathrm{R}$ Foundation for Statistical Computing, Auckland, New Zealand) scaled by the average STS risk score. Contrasts between groups were calculated by maximizing and profiling a log-linear Poisson likelihood treating the STS-PROM as a baseline rate multiplied by a group-specific rate. $P$ values are 1 degree of freedom likelihood ratio tests against the ratio of O:E being 1.0. We conducted sensitivity analyses for the validity of using a Poisson model versus a binomial model and using grouped versus individual level data in the statistical appendix. Model comparisons including the year, access approach, trial participation, and STS risk group as a predictor in a generalized linear model (Poisson likelihood log link) using the STS-PROM as an offset were compared to a base model with a common intercept using likelihood ratio tests. Analyses for learning effects (secular trend) were conducted using the regression model with (centered) year as a numeric variable. 


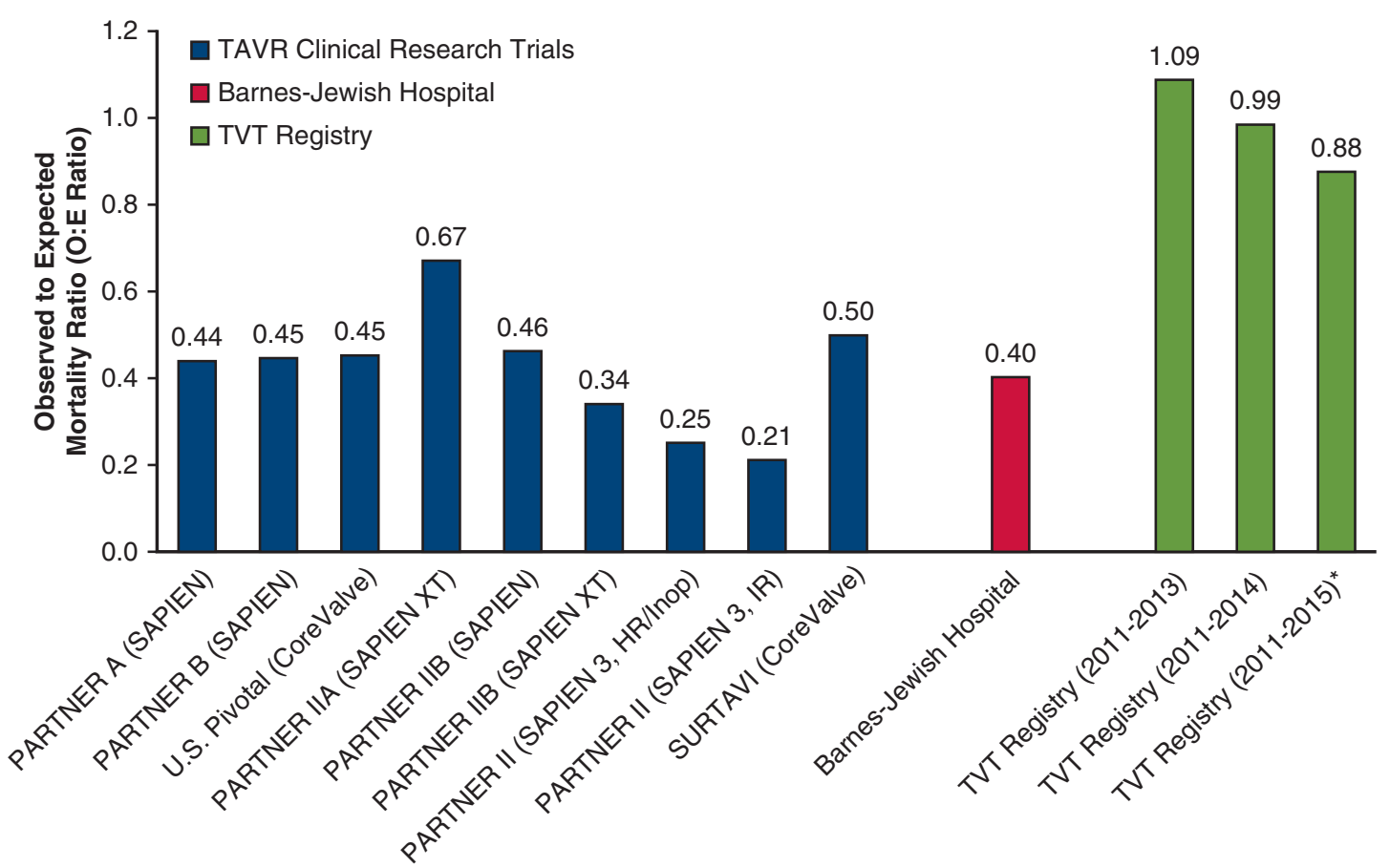

FIGURE 1. Observed to expected mortality ratios for transcatheter aortic valve replacement (TAVR) trials, the current study, and Transcatheter Valve Therapy (TVT) Registry. *Median Society for Thoracic Surgery Predicted Risk of Mortality (STS-PROM) risk score used for TVT Registry (2011-2015); 95\% confidence interval for Barnes-Jewish Hospital, 0.25-0.63. O:E ratio, Observed-to-expected 30-day mortality ratio.

\section{RESULTS}

\section{Patient Demographics and Procedural Details}

The patient demographics, procedural details, and perioperative complications are shown in Tables 1, E2, and E3. The average STS-PROM for the entire cohort $(\mathrm{N}=520)$ was $9.4 \%$. During the study period, there was a transition toward fewer alternative access procedures, with $77 \%$ of procedures in 2015 being performed using a TF approach. TA procedures were introduced in $2009(n=5)$ and peaked in $2012(n=36)$, accounting for $43 \%$ of total procedures that year. In addition, in 2012, the TAo procedure was introduced $(\mathrm{n}=5)$ and patients requiring a non-TF approach were preferentially treated with a TAo procedure when possible (Table 1).

\section{O:E Ratios Over Time and Access Approach}

The observed 30-day mortality for the entire group was $3.8 \%(20 / 520)$ and the average STS-PROM was $9.4 \%$, yielding an O:E ratio of 0.40 . The overall observed 30-day mortality for the entire series was significantly lower than the average STS-PROM $(P<.001)$, and the overall O:E ratio was significantly less than $1(P<.001 ; 95 \%$ confidence interval $[\mathrm{CI}], 0.25-0.63)$. When the $\mathrm{O}: \mathrm{E}$ ratio was broken down by year, there were no statistical differences for any given year when compared to any other year. The observed mortality was lower than the expected mortality for all years (Figure 2, A), providing O:E ratios less than 1.0 (Figure 2, B, Appendix Figures 1 and 3)-with most years demonstrating an O:E ratio less than 0.6. No significant temporal trend was identified, even after adjusting for commercial versus research status and optionally eliminating the initial year (statistical appendix).

When broken down by access approach (Figure 3), the $\mathrm{O}: \mathrm{E}$ ratios for 30-day mortality were similar for TF and TAo $(0.22 \quad[95 \%$ CI, $0.07-0.51]$ vs $0.40 \quad(95 \%$ CI, $0.13-0.91)$, respectively; $P=.35$ ). The TA group had the highest O:E ratio at 0.76 (95\% CI, 0.37-1.35), which

TABLE 1. Access Approach by Year

\begin{tabular}{|c|c|c|c|c|c|c|c|c|c|}
\hline Variable & $\begin{array}{c}2008 \\
(n=13)\end{array}$ & $\begin{array}{c}2009 \\
(n=11)\end{array}$ & $\begin{array}{c}2010 \\
(n=34)\end{array}$ & $\begin{array}{c}2011 \\
(n=54)\end{array}$ & $\begin{array}{c}2012 \\
(n=83)\end{array}$ & $\begin{array}{c}2013 \\
(n=91)\end{array}$ & $\begin{array}{c}2014 \\
(n=114)\end{array}$ & $\begin{array}{c}2015 \\
(n=146)\end{array}$ & $P$ value \\
\hline Transfemoral & $12(92 \%)$ & $6(55 \%)$ & $13(38 \%)$ & $29(54 \%)$ & $42(51 \%)$ & $28(31 \%)$ & $49(43 \%)$ & $113(77 \%)$ & $<.0001$ \\
\hline Transapical & $1(8 \%)$ & $5(45 \%)$ & $21(62 \%)$ & $25(46 \%)$ & $36(43 \%)$ & $17(19 \%)$ & $15(13 \%)$ & $10(7 \%)$ & \\
\hline Transaortic & 0 & 0 & 0 & 0 & $5(6 \%)$ & $46(50 \%)$ & $50(44 \%)$ & $20(14 \%)$ & \\
\hline Subclavian & 0 & 0 & 0 & 0 & 0 & 0 & 0 & $3(2 \%)$ & \\
\hline
\end{tabular}




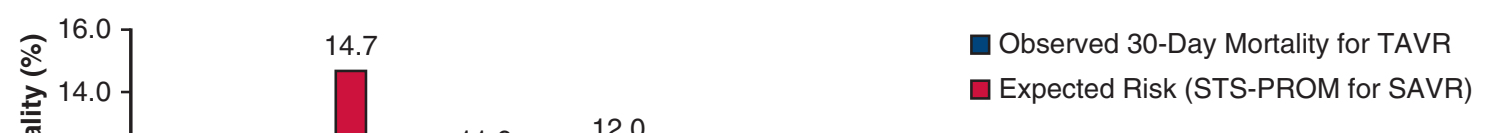

Observed 30-Day Mortality for TAVR
Expected Risk (STS-PROM for SAVR)

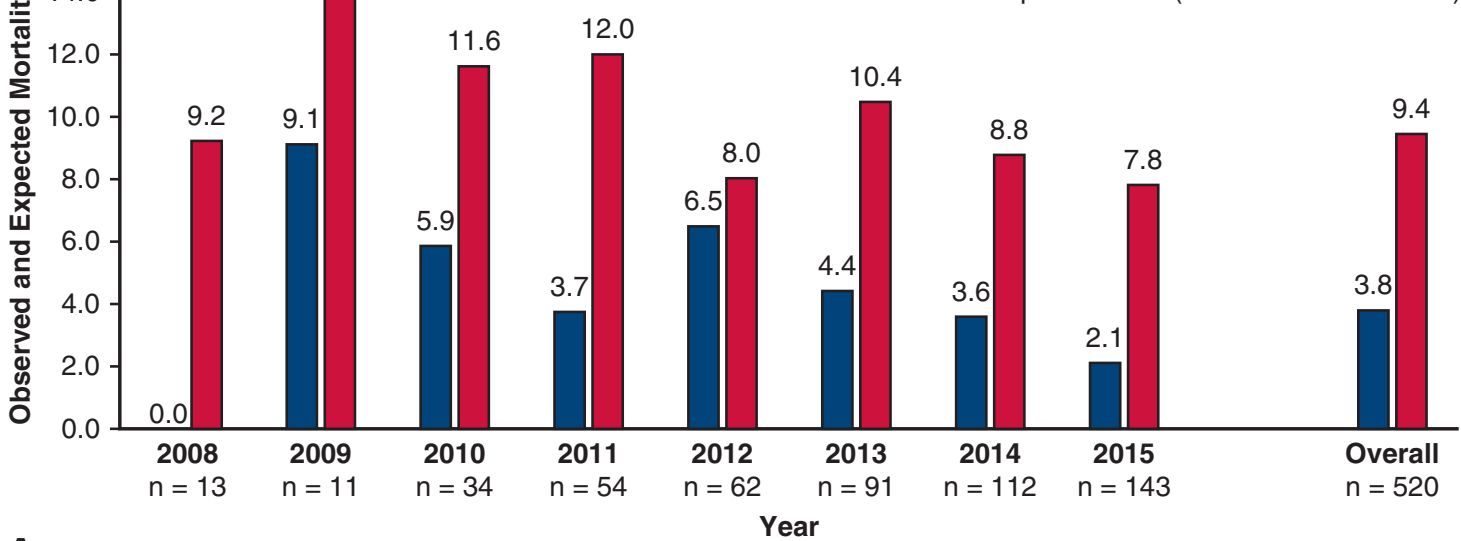

A

Year

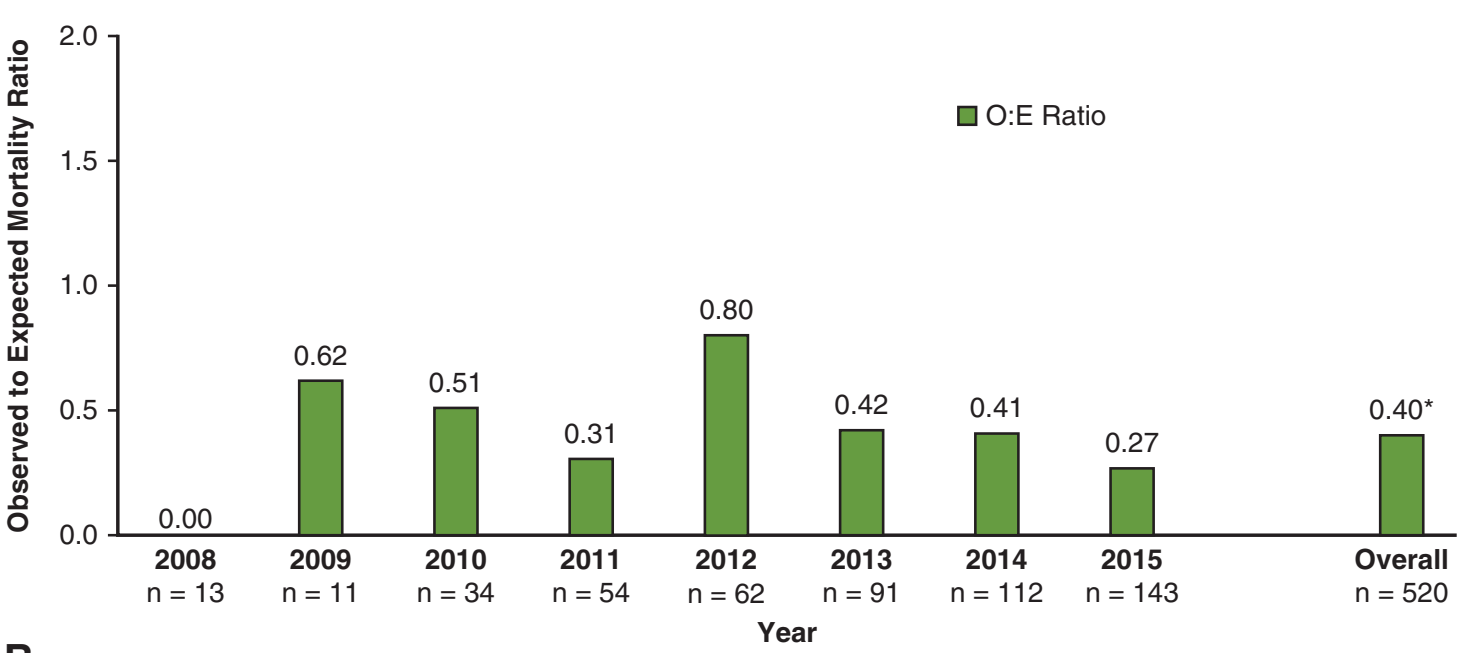

B

FIGURE 2. A, Expected and observed mortality by year. B, Observed-to-expected 30-day mortality $(O: E)$ ratio by year. *P<.001 when compared with an O:E ratio of 1 (95\% confidence interval for 2008, 0.0-2.67; for 2009, 0.02-2.81; for 2010, 0.06-1.7; for 2011, 0.04-1.07; for 2012, 0.22-1.96; for 2013, 0.121.04; for 2014, 0.11-1.01; and for 2015, 0.06-0.77). TAVR, Transcatheter aortic valve replacement; STS-PROM, Society for Thoracic Surgery Predicted Risk of Mortality; SAVR, surgical aortic valve replacement.

was significantly higher than in the TF group (0.76 vs $0.22 ; P=.018)$.

\section{Commercial Versus Research}

There was no difference in STS-PROM for patients undergoing TAVR whether they were enrolled in a clinical trial versus those undergoing a commercial implant $(9.3 \pm 5.5$ vs $9.4 \pm 5.0$, respectively; $P=.83)$. The 30 day mortality for these 2 groups were also similar $(8 / 263$ [3\%] vs $14 / 283$ [4.9\%], respectively; $P=.287$ ). The O:E ratios for research and commercial patients were similar when compared to each other $(0.32$ vs $0.50 ; P=.34)$, and both were significantly less than 1.0 (commercial O:E ratio, $0.50[P=.007 ; 95 \% \mathrm{CI} 0.26-0.86]$; and research O:E ratio, $0.32[P<.001 ; 95 \%$ CI, 0.14-0.63; Figure 4).

\section{Surgical Risk}

To evaluate the consistency of the O:E relationship among risk groups, the entire study group was stratified into low risk (STS-PROM $<4 ; \mathrm{n}=60$ ), moderate risk (STS$\mathrm{PROM}=4-8 ; \mathrm{n}=153$ ), and high risk (STS-PROM $>8$; $\mathrm{n}=305$ ). The O:E ratios for all risk groups were less than 0.5 and significantly less than 1.0 (low risk, $0.0[95 \% \mathrm{CI}$, 0.0-2.02]; moderate risk, 0.35 [95\% CI 0.07-0.99]; and high risk, 0.45 [95\% CI, 0.26-0.70]). There were no significant differences between any of groups (Figure 5).

\section{STS-PROM Version}

The mean of the recalculated STS-PROM (version 2.81) was not significantly different than the original mean (versions 2.61 or $2.73 ; 10.0 \pm 5.6$ vs $10.3 \pm 5.9 ; P=.691$; Figure E1). 


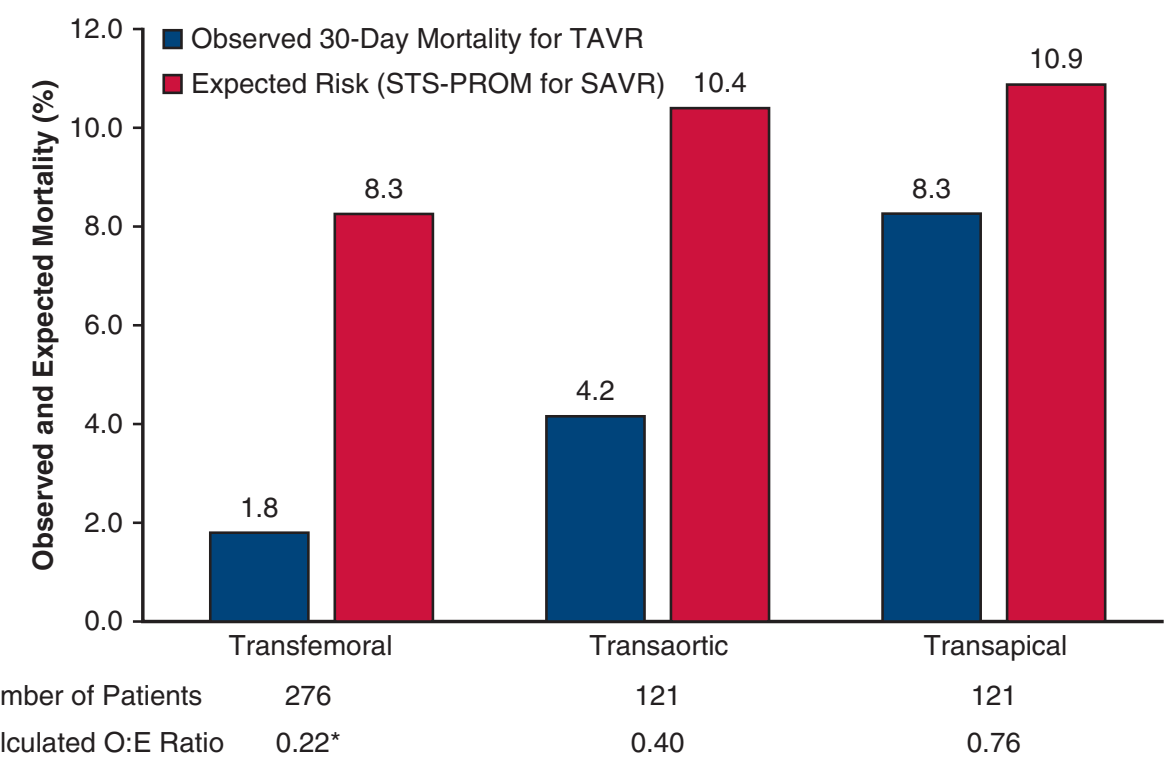

FIGURE 3. Expected and observed mortality by access approach. *Observed-to-expected 30-day mortality $(O: E)$ ratio for transfemoral was significantly less than transapical ( 0.22 vs $0.76 ; P=.02) ; 95 \%$ confidence intervals for transfemoral, 0.07-0.51; transapical, 0.37-1.35; and transaortic, 0.13-0.91). TAVR, Transcatheter aortic valve replacement; STS-PROM, Society for Thoracic Surgery Predicted Risk of Mortality; SAVR, surgical aortic valve replacement.

\section{DISCUSSION}

The principal finding of this manuscript is that within this single-institution experience encompassing the introduction of TAVR in 2008 and its evolution with subsequent advances in technology and technique, the overall O:E ratio for the entire series was 0.40 (Video 1). These results are consistent with the initial large, randomized trials evaluating the safety, feasibility, and efficacy of TAVR. These clinical trials demonstrated an O:E ratio between 0.21 and 0.67 suggesting that a significant survival advantage was

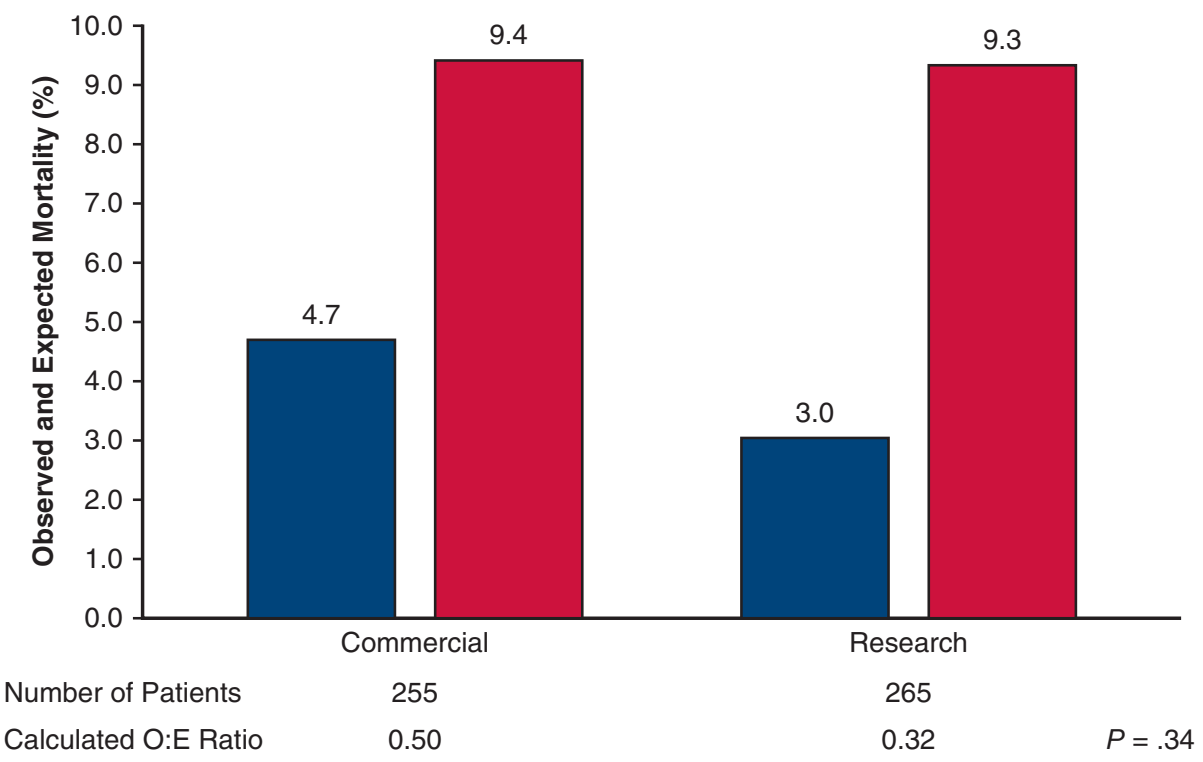

Observed 30-Day Mortality for TAVR

$\square$ Expected Risk (STS-PROM for SAVR)

FIGURE 4. Expected and observed mortality in commercial and research patient populations. (95\% confidence intervals for commercial, $0.26-0.86$; and research, 0.14-0.63). TAVR, Transcatheter aortic valve replacement; STS-PROM, Society for Thoracic Surgery Predicted Risk of Mortality; SAVR, surgical aortic valve replacement; $O: E$ ratio, observed-to-expected 30-day mortality ratio. 


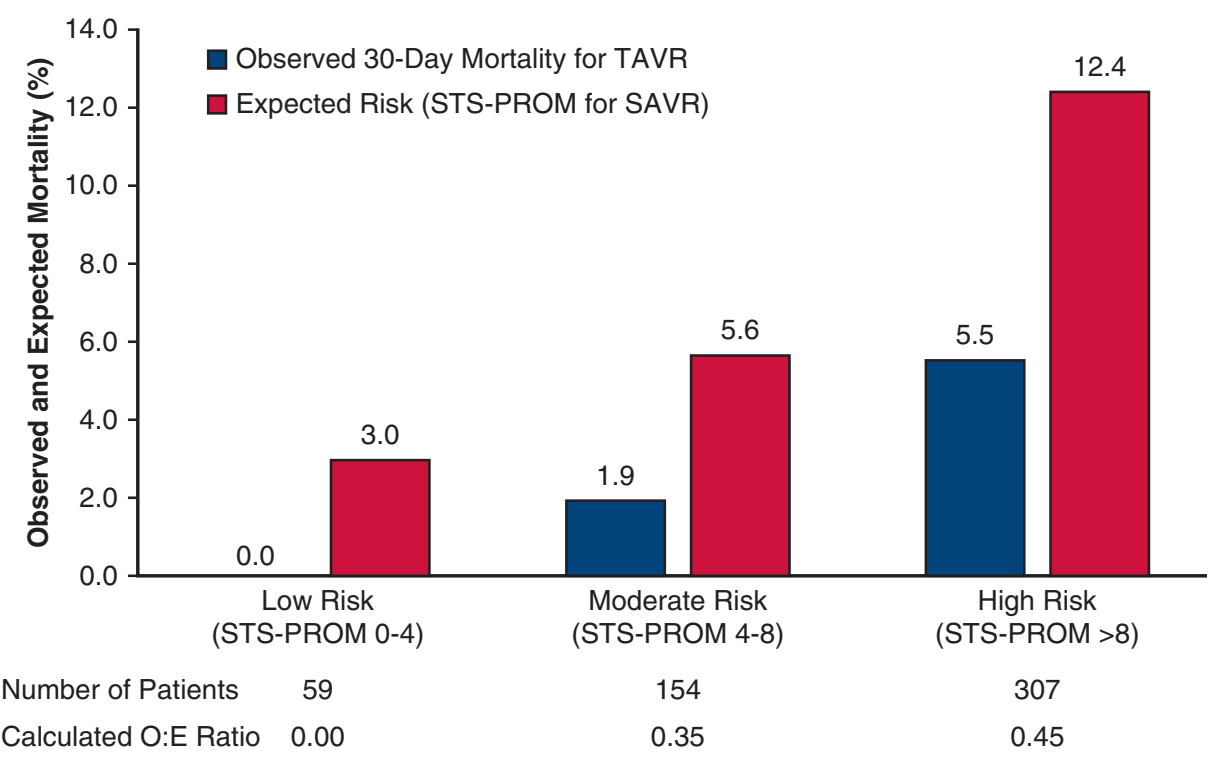

FIGURE 5. Expected and observed mortality by risk. (95\% confidence intervals for low risk, 0-2.02; moderate risk, 0.07-0.99; and high risk, 0.26-0.7). $T A V R$, Transcatheter aortic valve replacement; STS-PROM, Society for Thoracic Surgery Predicted Risk of Mortality; SAVR, surgical aortic valve replacement; $O: E$ ratio, observed-to-expected 30-day mortality ratio.

conferred with the TAVR procedure (Figure 1, Table E1). Furthermore, these results confirm that the STS-PROM for SAVR consistently overestimates risk for TAVR and suggest the need for a more accurate TAVR risk calculator. $^{3-5,13-16,24}$ In fact, it is these excellent, early results that have led to the early adoption and widespread dissemination of the TAVR procedure.

Most importantly, this investigation demonstrated that there was no significant difference in TAVR mortality, when evaluated by the O:E ratio metric, regardless of whether patients were enrolled as part of a clinical trial or simply receiving a commercial implant as part of the TVT Registry. While a Hawthorne effect cannot be excluded from a single study at a single center, the results of this investigation would suggest that the additional scrutiny or

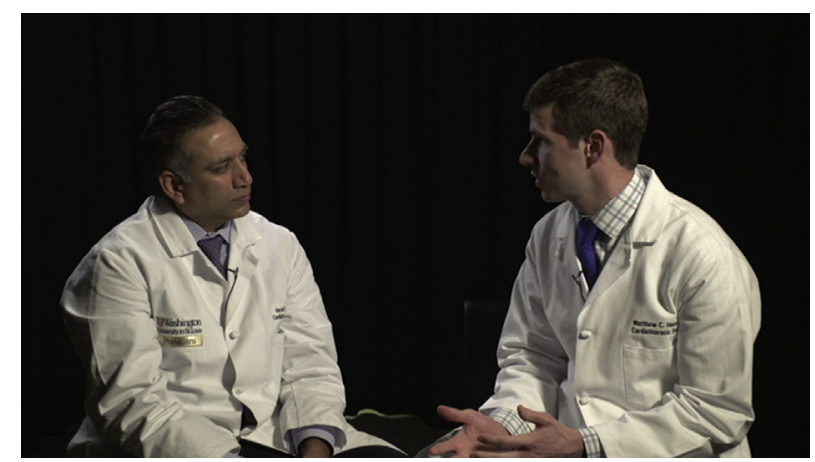

VIDEO 1. The principal findings and implications of this study are discussed. Video available at: https://www.jtcvs.org/article/S00225223(18)32031-2/fulltext. often best practices afforded patients within a clinical trial did not confer any additional survival benefit to TAVR patients when compared with commercial patients. Both the research and commercial patients in this study demonstrated an excellent 30-day mortality with an O:E ratio far less than that reported by publications from the TVT registry. In 2013, results from the TVT registry had an average STS-PROM of 7 in regard to patient risk, but demonstrated a 30-day mortality of $7.6 \%$, yielding an $\mathrm{O}: \mathrm{E}$ ratio of $1.09 .^{21}$ While this analysis was limited in that only $51 \%$ of participating hospitals provided 30-day mortality data, subsequent updates from the TVT remain consistent with reports from 2011 to 2014 demonstrating an O:E ratio of $0.99 .{ }^{19}$ Most recently, TVT reports have demonstrated a median STS-PROM of 6.5 and a 30-day mortality of $5.7 \%$, with an O:E ratio of 0.88 (Table E1). Although this result suggests improvements in TVT O:E ratios, the data remain incomplete, with approximately $20 \%$ of enrolled patients lacking 30-day mortality data and the STS-PROM reported as a median instead of a mean, which likely artificially lowers the O:E ratio. ${ }^{18}$

A similarity between our study and the TVT registry was identified when results were broken down by access route. The O:E ratios for TAVR procedures performed with a TA approach in this study demonstrated worse outcomes for TAVR. This was similarly shown, perhaps even magnified, in reporting from the TVT in which O:E ratios for alternative access procedures had $\mathrm{O}: \mathrm{E}$ ratios greater than 1 for both the inoperable $(\mathrm{O}: \mathrm{E}=1.8)$ and high-risk $(\mathrm{O}: \mathrm{E}=1.5)$ patient groups. $^{21}$ The increased mortality associated with TA in our series is the most likely 
explanation for the elevated O:E risk seen during 2012, when TA procedures were at their peak.

With the significant increase in number of TAVR centers across the United States, there has been a concerted effort to identify a learning curve for the procedure, with reports from this institution and others identifying a total of 25 to 50 cases to reach proficiency ${ }^{18,25-27}$ During the early part of the TVT registry collection period, the median total case volume annually for centers offering TAVR was 17 , a period in which the overall in-hospital mortality increased from $3.5 \%$ to $5.2 \% .{ }^{11,28}$ As TAVR volumes have increased, the implication that TAVR numbers at a given center have equally increased is not certain given the rapid expansion in the number of TAVR centers nationally. ${ }^{18}$ If procedural outcomes continue to improve, as some centers have suggested, even beyond more than 100 cases, ${ }^{11,29}$ smaller centers will continue to have difficulty to surpass their learning curve in regard to patient selection and technical performance.

The Centers for Medicare and Medicaid Services has announced a shift in reimbursement schemes toward payment models that are based on value of care, rather than volume. ${ }^{30}$ The results from this study and the large, randomized trials for TAVR highlight the weaknesses of using the STS-PROM to predict 30-day mortality for TAVR. Although risk models specific to TAVR have been developed using the TVT data, their predictive performance is based on in-hospital mortality, which makes comparisons to SAVR or early TAVR trials difficult. ${ }^{31,32}$ A current benchmark for maintaining a TAVR program for extreme risk patients is a $60 \%$ 1-year survival, which may be outdated given that lower risk patients are currently being offered with TAVR. Until an accurate and specific risk calculator for 30-day mortality is developed, our results and data from large, randomized trials suggest that programs use an O:E ratio closer to 0.6, based on the STS-PROM, as a benchmark for programs to achieve. The current TVT results suggest that there is a higher mortality after commercial TAVR than should be expected, and that programs are offering TAVR with suboptimal outcomes.

This study was limited by its retrospective nature and as a single-institutional study with observational comparisons to larger, randomized studies, making it subject to biases inherent in nonrandomized studies. The STS-PROM risk calculator changed over the course of the study period, which could confound results and observational comparisons to larger trials; however, recalculated STS-PROM scores were not significantly different in our dataset. The subgroup analyses were limited by sample size, multiple comparisons without adjustment, and lack of accounting for potential confounding variables, which limited statistical comparisons. Lastly, as an experienced TAVR center that participated in the initial TAVR trials in the United States this data is likely not applicable to all centers regardless of their institutional volume.

In conclusion, the STS-PROM consistently overestimates 30-day mortality after TAVR in both the present study and large, randomized TAVR trials. Until a better metric for TAVR performance is identified, the O:E ratio provides an acceptable metric to evaluate registry results and individual program 30-day performance. The results of this investigation and early multicenter trials suggest that an O:E ratio benchmark of less than 0.6 may be a reasonable starting point by which programs can judge their own results. The current, significantly elevated O:E ratios for 30-day mortality reported from the TVT registry suggest that there are programs offering the TAVR procedure to patients without the benefit previously seen with this minimally invasive procedure.

\section{Webcast}

You can watch a Webcast of this AATS meeting presentation by going to: https://aats.blob.core.windows.net/ media/17AM/2017-05-01/RM306/05-01-17_Room306_ 1456_Henn.mp4.

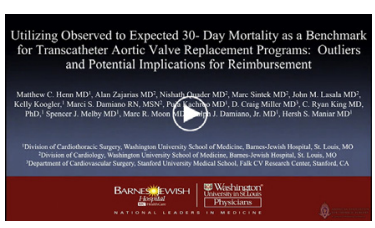

\section{Conflicts of Interest Statement}

Dr D. Craig Miller serves as a consultant for Medtronic, Inc, outside the submitted work, and reports grants/personal fees/ non-financial support/other from Abbott Vascular for Stanford Co-PI, Coapt, MitraClip trails; Edwards Lifesciences, LLC for Stanford PI-PARTNER and COMMENCE trials; and Medtronic Core Valve for Stanford PI-SURTAVI trial outside the submitted work. Dr Alan Zajarias serves as a consultant for Edwards Lifesciences and as an Educator for Medtronic outside the submitted work. Dr Marc Sintek serves as Advisory Board for Boston Scientific and reports personal fees from Volcano Corporation outside the submitted work. Dr Ralph Damiano Jr serves as a Consultant for AtriCure and report receiving educational funding from Edwards Lifesciences outside the submitted work. Dr Marc Moon serves as a speaker for Medtronic outside the submitted work. Dr John Lasala serves as a speaker and advisory board for Abbott outside the submitted work and reports grants/personal fees/ nonfinancial support/other from Boston Scientific and Abiomed outside the submitted work. All other authors have nothing to disclose with regard to commercial support.

\section{References}

1. Shahian DM, Jacobs JP, Edwards FH, Brennan JM, Dokholyan RS, Prager RL, et al. The society of thoracic surgeons national database. Heart. 2013;99: 1494-501. 
2. Cribier A, Eltchaninoff H, Bash A, Borenstein N, Tron C, Bauer F, et al. Percutaneous transcatheter implantation of an aortic valve prosthesis for calcific aortic stenosis: first human case description. Circulation. 2002;106:3006-8.

3. Adams DH, Popma JJ, Reardon MJ, Yakubov SJ, Coselli JS, Deeb GM, et al. Transcatheter aortic-valve replacement with a self-expanding prosthesis. N Engl J Med. 2014;370:1790-8.

4. Leon MB, Smith CR, Mack M, Miller DC, Moses JW, Svensson LG, et al. Transcatheter aortic-valve implantation for aortic stenosis in patients who cannot undergo surgery. N Engl J Med. 2010;363:1597-607.

5. Smith CR, Leon MB, Mack MJ, Miller DC, Moses JW, Svensson LG, et al. Transcatheter versus surgical aortic-valve replacement in high-risk patients. N Engl J Med. 2011;364:2187-98.

6. Decision Memo for Transcatheter Aortic Valve Replacement (TAVR) (CAG00430N). Available at: https://www.cms.gov/medicare-coverage-database/ details/nca-decision-memo.aspx NCAId $=257 \& v e r=4 \&$ NcaName $=$ Transcatheter + Aortic + Valve + Replacement $+($ TAVR $) \& b c=$ ACAAAAAAIAAA\&. Accessed March 6, 2017.

7. FDA approves expanded indication for two transcatheter heart valves for patients at intermediate risk for death or complications associated with openheart surgery. Available at: https://www.fda.gov/NewsEvents/Newsroom/Press Announcements/ucm517281.htm. Accessed March 6, 2017.

8. Dewey TM, Brown D, Ryan WH, Herbert MA, Prince SL, Mack MJ. Reliability of risk algorithms in predicting early and late operative outcomes in high-risk patients undergoing aortic valve replacement. J Thorac Cardiovasc Surg. 2008; 135:180-7.

9. Biancari F, Juvonen T, Onorati F, Faggian G, Heikkinen J, Airaksinen J, Mariscalco G. Meta-analysis on the performance of the EuroSCORE II and the Society of Thoracic Surgeons Scores in patients undergoing aortic valve replacement. J Cardiothorac Vasc Anesth. 2014;28:1533-9.

10. Englum BR, Ganapathi AM, Schechter MA, Harrison JK, Glower DD, Hughes GC. Changes in risk profile and outcomes of patients undergoing surgical aortic valve replacement from the pre- to post-transcatheter aortic valve replacement eras. Ann Thorac Surg. 2016;101:110-7.

11. Brennan JM, Holmes DR, Sherwood MW, Edwards FH, Carroll JD, Grover FL, et al. The association of transcatheter aortic valve replacement availability and hospital aortic valve replacement volume and mortality in the United States. Ann Thorac Surg. 2014;98:2016-22; discussion 2022.

12. Kodali SK, Williams MR, Smith CR, Svensson LG, Webb JG, Makkar RR, et al. Two-year outcomes after transcatheter or surgical aortic-valve replacement. N Engl J Med. 2012;366:1686-95.

13. Kodali S, Thourani VH, White J, Malaisrie SC, Lim S, Greason KL, et al. Early clinical and echocardiographic outcomes after SAPIEN 3 transcatheter aortic valve replacement in inoperable, high-risk and intermediate-risk patients with aortic stenosis. Eur Heart J. 2016;37:2252-62.

14. Thourani VH, Kodali S, Makkar RR, Herrmann HC, Williams M, Babaliaros V, et al. Transcatheter aortic valve replacement versus surgical valve replacement in intermediate-risk patients: a propensity score analysis. Lancet. 2016;387: 2218-25.

15. Webb JG, Doshi D, Mack MJ, Makkar R, Smith CR, Pichard AD, et al. A randomized evaluation of the SAPIEN XT transcatheter heart valve system in patients with aortic stenosis who are not candidates for surgery. JACC Cardiovasc Interv. 2015;8:1797-806.

16. Reardon MJ, Van Mieghem NM, Popma JJ, Kleiman NS, Sondergaard L, Mumtaz M, et al. Surgical or transcatheter aortic-valve replacement in intermediate-risk patients. $N$ Engl J Med. 2017;376:1321-31.

17. Carroll JD, Edwards FH, Marinac-Dabic D, Brindis RG, Grover FL, Peterson ED, et al. The STS-ACC transcatheter valve therapy national registry: a new partnership and infrastructure for the introduction and surveillance of medical devices and therapies. J Am Coll Cardiol. 2013;62:1026-34.

18. Grover FL, Vemulapalli S, Carroll JD, Edwards FH, Mack MJ, Thourani VH, et al. 2016 annual report of the Society of Thoracic Surgeons/American College of Cardiology transcatheter valve therapy registry. Ann Thorac Surg. 2017;103:1021-35.

19. Holmes DR Jr, Brennan JM, Rumsfeld JS, Dai D, O'Brien SM, Vemulapalli S, et al. Clinical outcomes at 1 year following transcatheter aortic valve replacement. JAMA. 2015;313:1019-28.

20. Holmes DR Jr, Nishimura RA, Grover FL, Brindis RG, Carroll JD, Edwards FH, et al. Annual outcomes with transcatheter valve therapy: from the STS/ACC TVT Registry. Ann Thorac Surg. 2016;101:789-800.

21. Mack MJ, Brennan JM, Brindis R, Carroll J, Edwards F, Grover F, et al. Outcomes following transcatheter aortic valve replacement in the United States. JAMA. 2013;310:2069-77.
22. Online STS Adult Cardiac Surgery Risk Calculator. Available at: http://riskcalc sts.org/stswebriskcalc/\#/calculate. Accessed April 4, 2017.

23. Adult Cardiac Surgery Database Data Collection. Available at: http://www.sts org/sts-national-database/database-managers/adult-cardiac-surgery-database/ data-collection. Accessed April 8, 2017.

24. Leon MB, Smith CR, Mack MJ, Makkar RR, Svensson LG, Kodali SK, et al. Transcatheter or surgical aortic-valve replacement in intermediate-risk patients. N Engl J Med. 2016;374:1609-20.

25. Alli O, Rihal CS, Suri RM, et al. Learning curves for transfemoral transcatheter aortic valve replacement in the PARTNER-I trial: technical performance. Catheter Cardiovasc Interv. 2016;87:154-62.

26. Henn MC, Percival T, Zajarias A, Melby SJ, Lindman BR, Quader N, et al Learning alternative access approaches for transcatheter aortic valve replacement: implications for new transcatheter aortic valve replacement centers. Ann Thorac Surg. 2017;103:1399-405.

27. Gurvitch R, Tay EL, Wijesinghe N, Ye J, Nietlispach F, Wood DA, et al Transcatheter aortic valve implantation: lessons from the learning curve of the first 270 high-risk patients. Catheter Cardiovasc Interv. 2011;78:977-84.

28. Murugiah K, Wang Y, Desai NR, Nuti SV, Krumholz HM. Hospital variation in outcomes for transcatheter aortic valve replacement among medicare beneficiaries, 2011 to 2013. J Am Coll Cardiol. 2015;66:2678-9.

29. Carroll JVS, Dai D, Matsouka R, Blackstone E, Edwards F, Masoudi F, et al. Relationship between procedure volume and outcome for transcatheter aortic valve replacement in U.S. clinical practice: insights from the STS/ACC TVT Registry. Chicago: American College of Cardiology; 2016.

30. CMS and major commercial health plans, in concert with physician groups and other stakeholders, announce aligment and simplification of qualiy measures. Available at: https://www.cms.gov/Newsroom/MediaReleaseDatabase/Pressreleases/2016-Press-releases-items/2016-02-16.html. Accessed April 10, 2017.

31. Edwards FH, Cohen DJ, O'Brien SM, Peterson ED, Mack MJ, Shahian DM, et al. Development and validation of a risk prediction model for in-hospital mortality after transcatheter aortic valve replacement. JAMA Cardiol. 2016;1:46-52.

32. O'Brien SM, Cohen DJ, Rumsfeld JS, Brennan JM, Shahian DM, Dai D, et al. Variation in hospital risk-adjusted mortality rates following transcatheter aortic valve replacement in the United States: a report from the Society of Thoracic Surgeons/American College of Cardiology transcatheter valve therapy registry. Circ Cardiovasc Qual Outcomes. 2016;9:560-5.

Key Words: aortic valve replacement, TAVR, aortic stenosis, survival

\section{Discussion}

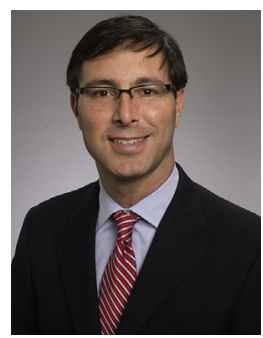

Dr Michael Halkos (Atlanta, Ga). Very nice work and thank you very much for sending the paper so I could review it. The general conclusions in addition to what you showed is that transcatheter aortic valve replacement (TAVR) at your institution is associated with excellent teamwork between your interventionalists and your interventional surgeons. Congratulations to the group for achieving outstanding results.

As you also showed, the TAVR Registry, which is a broad, widespread report of what is being done in real practice, is much more realistic, may include programs that are just starting, and maybe even lower-volume programs. Their odds ratios are about 1 .

When you see a presentation like this, a couple of questions come to mind. What are we supposed to do with these data? You are able to achieve an observed-to-expected 
30-day mortality ratio of 0.6 , probably like other high-volume centers. If you look at the initial trends, which have improved since 2009 when TAVR was first initiated at your institution, with time those have gotten remarkably better and hopefully we will see that with all participating sites in the TAVR Registry. Are we ready to change thresholds or set benchmarks based on the expert centers, or should we continue to support the establishing or gradually adopting centers?

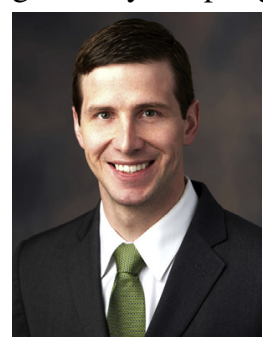

Dr Matthew C. Henn (St. Louis, Mo). That's a very good question. This is opening a conversation about points you alluded to; namely, should we be establishing benchmarks by only looking at the high-volume centers, or should we look at the broad volume nationally to establish benchmarks, particularly in respect to mortality. This warrants further scrutiny. Moving forward as TAVR volumes increase, a lot of folks have looked at whether volume of TAVR procedures influences outcomes and a lot of folks have shown that. In the initial reports from the Transcatheter Valve Therapy (TVT) Registry from 2011 to 2013, the median case volume per center was 17 . Is that enough to beat their learning curve? Probably not.

So the question moving forward is, are these smaller volume centers going to increase their volume and are we going to see an improvement in the TVT Registry? I think that is yet to be answered.

Dr Halkos. One other question and 1 other comment. Society of Thoracic Surgeons Predicted Risk Of Mortality (STS-PROM) algorhythm has been used to help calculate these observed or predicted risks of mortality ratios, so was there anything in STS-PROM that you examined, anything that may not be applicable to the TAVR population, specifically the transfemoral population, which we would otherwise use for surgical aortic valve replacement patients? Have you been able to look at that or do you have any plans to do so?

Dr Henn. That's a very good question. We didn't specifically look at the individual contributions to the STS-PROM, but that's certainly something that would be valuable to look at.

Dr Halkos. A last comment for the group: We have to be careful before we start raising the bar too high, too quickly for an already relatively low-contributing margin procedure for hospitals if reimbursements are going to be based on higher thresholds for quality - and we should be aiming for that. There is already very little profit margin for these types of procedures in any of these hospitals.

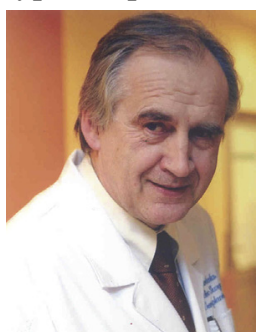

Dr Marian Zembala (Zabrze, Poland). Thank you for the message from your presentation. Do you agree (this is the first question) that nowadays the difference between observed and a predicted mortality (STS-PROM score) for TAVR is not that important? Some important factors for TAVR (eg, porcelain aorta, previous coronary artery bypass graft surgery with patent graft, and severe aortic stenosis), sometimes put patients at intermediate risk for surgery. But those you do not consider for the classification. That's my first question.

Second are comments. Do you agree from your perspective as a young resident, and there are many young residents at this table, that TAVR should be part of the surgical armamentarium? Including the transfemoral approach, which should be also done by a cardiac surgeon as operator in TAVR teams? We should prepare ourselves and teach resident physicians during cardiac surgery residency training programs that TAVR is also among the surgical procedures available to patients. Today, TAVR procedure is important and should be included in cardiovascular and cardiothoracic surgery residency training programs.

Dr Henn. Thank you for your questions. I definitely think there are aspects of the TAVR procedure that aren't encompassed in the STS-PROM for surgical aortic valve replacement. That, along with our data and data from large randomized trials, suggest that we need a new TAVR risk model. There have been proposed risk models for TAVR based on the TVT Registry data that I just showed you, or mainly based on inhospital mortality and not 30day mortality. So yes, there are aspects of the TAVR procedure that probably portend higher risk that are not included in the STS-PROM.

I agree with you. Moving forward, we need to really think hard about how we are training people to do the procedure. We need to start thinking about how we are going to start training the next generation of cardiac surgeons to do the procedure so we can stay involved. 
APPENDIX. SUPPLEMENTAL STATISTICAL METHODS

The primary data compared in this study are ratios of observed mortality to expected mortality as predicted from the average STS-PROM risk score. To evaluate and compare these ratios, we defined 2 log-linear models for the data. The first is a group level (collapsed) analysis matching what we would be able to do with
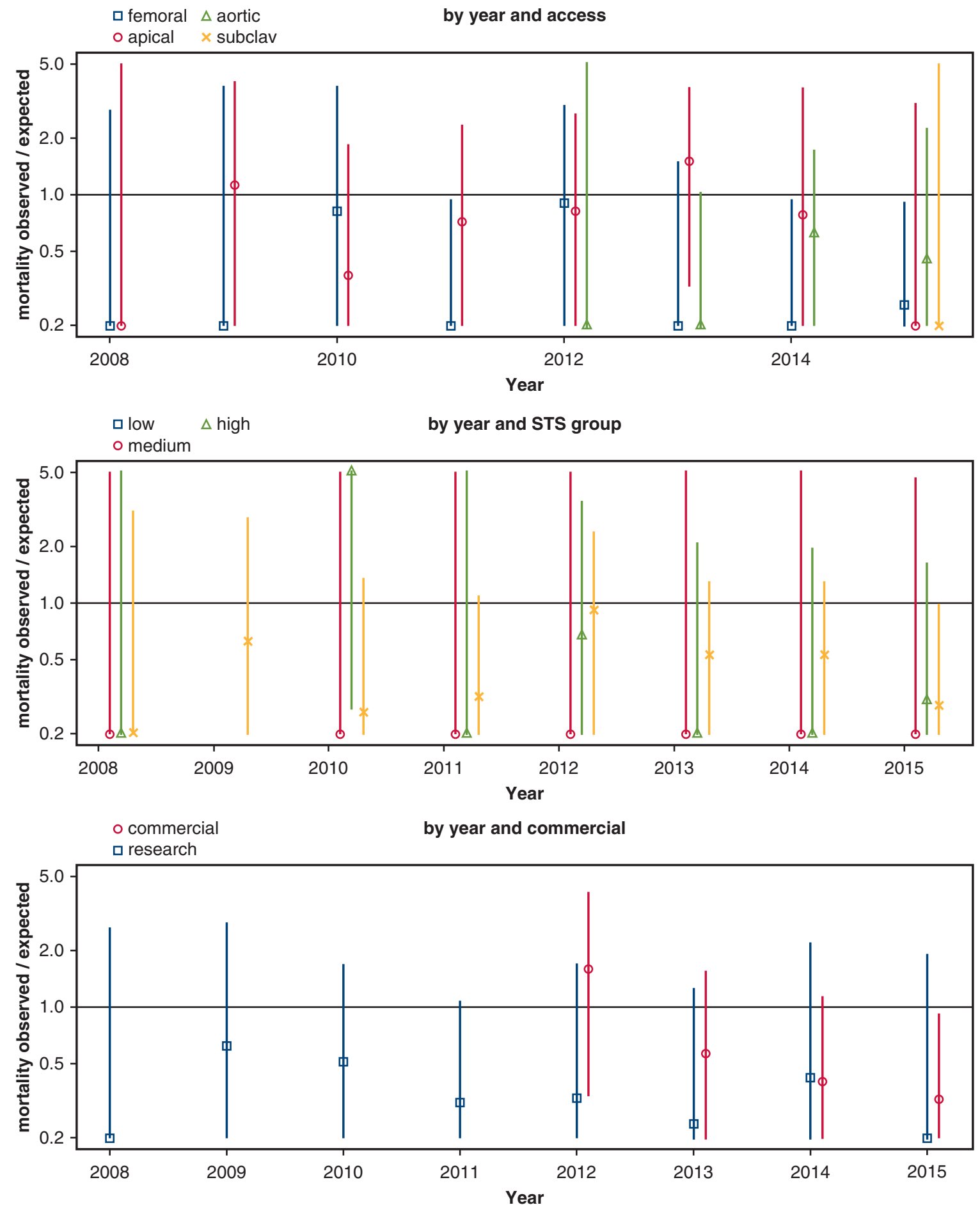

APPENDIX FIGURE 1. O:E ratios stratified by year and other risk factors. O:E ratios calculated using the collapsed method with Poisson likelihood and profile likelihood-based CIs for each combination of year and a secondary risk factor. $P>.1$ for all interaction terms using Poisson generalized linear model and likelihood ratio tests. STS, Society for Thoracic Surgery. 


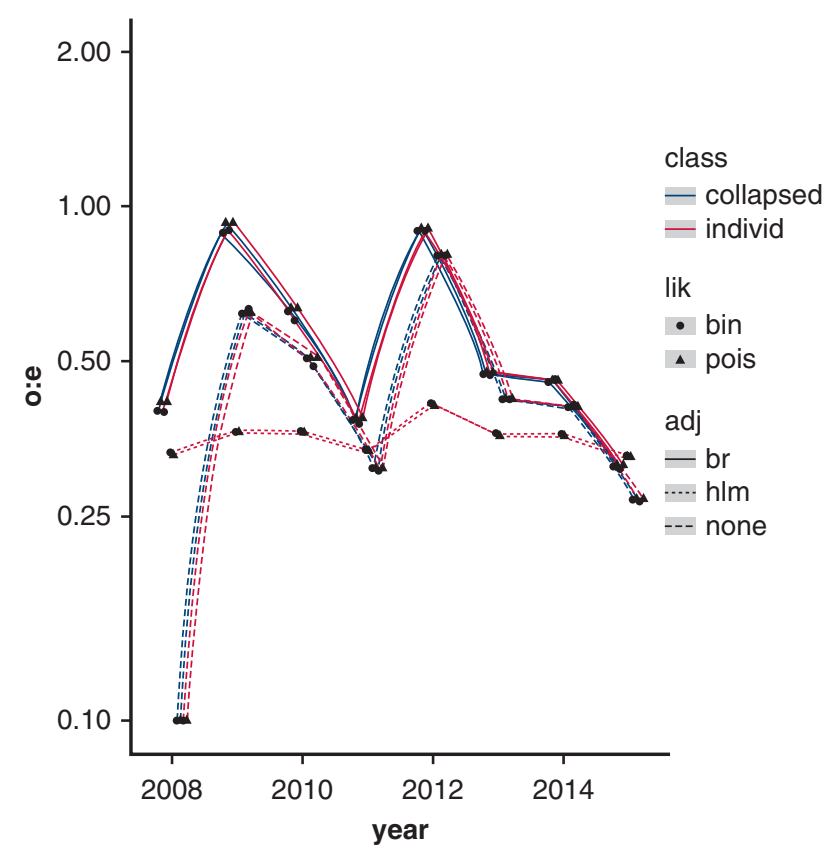

APPENDIX FIGURE 2. Point estimates of O:E ratios by year for various statistical methodologies. o:e, Observed-to-expected 30-day mortality; lik, likelihoods; adj, adjustments; bin, binomial likelihood; pois, Poisson likelihood; $b r$, firth bias reduction correction adjustment; $h l m$, hierarchical linear model.

center-level summaries. Specific statistical methodology included defining $i$ in $1 \ldots \mathrm{I}$ indexing the year, $n$ in $1 \ldots \mathrm{N}$ as indexing the participants, $a_{n}$ as the STS score for participant $n$, and $\bar{a}_{i}$ as the average risk score for all participants in year $i$. We then define the O:E ratio for year $i$ as $\gamma i=y_{i n} / \bar{a}_{i}$.

First, we describe the collapsed (summary statistics) method. If we take $y_{i n}$ to be independent Bernoulli trials with common mean $\widehat{f}_{i}$, then the observed mortality events in a year are binomially distributed. We can then use direct likelihood calculation to find the maximum likelihood estimation of $\widehat{f}_{i}$ and its likelihood-based confidence intervals. These estimates are then scaled by $\bar{a}_{i}$ to yield values for $\widehat{\gamma}_{\mathrm{i}}$. Tests of $\mathrm{O}=\mathrm{E}$ are tests of $\gamma=1\left(f_{i}=\bar{a}_{i}\right)$, which are simple tests of the binomial mean which are implemented in R's binom.test and prop.test.

Estimates of $\gamma$ are also obtained by formulating a generalized linear model (GLM) with a log-linear model for the mean: $\log \left(E\left[y_{i}\right]\right)=\log \left(\bar{a}_{i}\right)+\beta_{i}$. Exponentiating and dividing, we recover O:E $=\exp \exp \left(\beta_{i}\right)$. We implement this GLM with both a log-link binomial model and a loglink Poisson model approximating the binomial(N,f) as Poisson $(\mathrm{N} * \mathrm{f})$. The Poisson approximation was chosen for numerical stability because some years had no events, and because log-link binomial models can encounter boundary problems when using offsets. We used Firth score

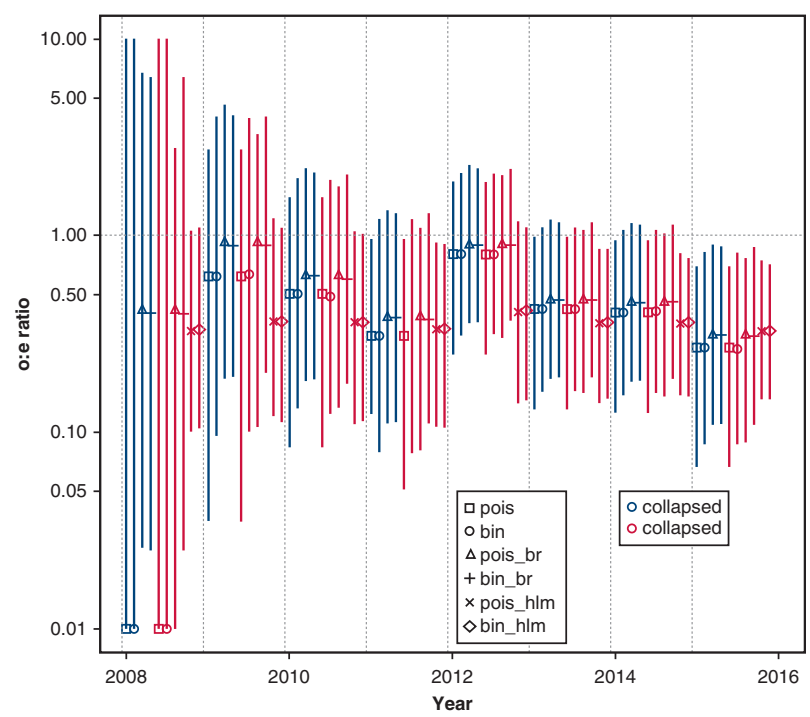

APPENDIX FIGURE 3. Point estimates of O:E ratios with confidence intervals by year for various statistical methodologies. o:e, Observed-toexpected 30-day mortality; pois, Poisson likelihood; bin, binomial likelihood; pois_br, Poisson likelihood with firth bias reduction correction adjustment; $b i n \_b r$, binomial likelihood with firth bias reduction correction adjustment; pois_hlm, Poisson likelihood with hierarchical linear model; bin_hlm, binomial likelihood with hierarchical linear model.

correction, which decreases bias of maximum likelihood estimations for binomial models and stabilizes estimates with complete separation (such as years with no events). Confidence intervals on $\backslash \exp \left(\beta_{i}\right)$ and tests of $\beta_{i}=0$ (ie, $\mathrm{O}=\mathrm{E})$ were generated using profile likelihood where numerically stable and using Wald-type calculations otherwise. Pairwise tests of $\beta_{i}-\beta_{k}=0$ were similarly generated with likelihood ratio tests when possible and Wald tests otherwise. Comparison of unequal $\beta_{i}$ versus a common value, a common value plus linear trend, and all $\beta=0$ were also generated by likelihood ratio test. Tests and intervals for a linear trend were also conducted with a negativebinomial link to account for idiosyncratic variation in treatment effect by year.

Since the collapsed model uses only summary statistics, it ignores the person-level variation in risk. In addition, grouping variables such as the surgeon, anesthesiologist, and cardiologist were unable to be accounted for making the model calculations somewhat liberal.

We next define a person-level regression model with year-specific effects, which also yields an O:E interpretation. The log-linear model for the mean is: $\log \left(E\left[y_{i n}\right]\right)=\log ($ in $)+\beta_{i}$ Year $_{\text {in }}$. Similarly, a Bernoulli likelihood with log link and an independent Poisson model were computed. Note that O:E ratio models are inherently nonlinear, and we do not expect the collapsed and 
APPENDIX TABLE 1. O:E ratios by risk factor

\begin{tabular}{|c|c|c|c|c|}
\hline & O:E & Lower CI & Upper CI & $P$ Value \\
\hline \multicolumn{5}{|l|}{ Year } \\
\hline 2008 & 0 & 0 & 2.67 & .625 \\
\hline 2009 & 0.62 & 0.02 & 2.81 & 1 \\
\hline 2010 & 0.51 & 0.06 & 1.7 & .424 \\
\hline 2011 & 0.31 & 0.04 & 1.07 & .06 \\
\hline 2012 & 0.8 & 0.22 & 1.96 & .817 \\
\hline 2013 & 0.42 & 0.12 & 1.04 & .059 \\
\hline 2014 & 0.41 & 0.11 & 1.01 & .063 \\
\hline 2015 & 0.27 & 0.06 & 0.77 & .007 \\
\hline \multicolumn{5}{|l|}{ STS Risk Group } \\
\hline Low & 0 & 0 & 2.02 & .427 \\
\hline Med & 0.35 & 0.07 & 0.99 & .052 \\
\hline High & 0.45 & 0.26 & 0.7 & $<.001$ \\
\hline \multicolumn{5}{|c|}{ Access Approach } \\
\hline Femoral & 0.22 & 0.07 & 0.51 & $<.001$ \\
\hline Apical & 0.76 & 0.37 & 1.35 & .464 \\
\hline Aortic & 0.4 & 0.13 & 0.91 & .024 \\
\hline Subclavian & 0 & 0 & 11 & 1 \\
\hline \multicolumn{5}{|l|}{ Trial Status } \\
\hline Commercial & 0.32 & 0.14 & 0.63 & $<.001$ \\
\hline Research & 0.5 & 0.26 & 0.86 & .007 \\
\hline
\end{tabular}

O:E, Observed-to-expected 30-day mortality; $C I$, confidence interval; STS, Society of Thoracic Surgeons.

individual level results to be identical because they aggregate information on different scales. To preserve the O:E ratio interpretation using the STS risk scores, $\log (a)$ is entered into the model as an offset (ie, its coefficient is fixed at one).

We conducted a sensitivity analysis comparing the above model fitting options, and since we found no substantive difference, we report the collapsed models using the Poisson approximate likelihood in the manuscript.

We also performed a sensitivity check using hierarchical regression for shrinkage of the year effects. We implemented the model $\log \left(E\left[y_{i n}\right]\right)=\log ($ in $)+\beta_{i}$ year $_{i n}+\alpha t_{n}+\mu$ where $t_{n}$ encodes the difference between the procedure date and 2010. The priors used were: $\alpha, \mu$, an automatically scaled Cauchy, $\beta$ distributed normally with zero mean, and standard deviation distributed gamma $(1,1)$. We used both a binomial likelihood with log link and a Poisson likelihood. Posterior means and 95\% credible intervals are reported. Models were fit by Hamiltonian Monte Carlo with 4 chains and a total of 4000 iterations each after warmup (effective size $\sim 2500$ for each parameter). Diagnostics of Markov chain Monte Carlo convergence including Rubin-Gelman and Rhat were inspected. Because 2008 could be seen as an outlying event, we conducted a sensitivity analysis for the secular trend deleting it.

The preceding discussion focuses on year of procedure as the predictive factor variable; the same analysis is performed with other predictor variables (eg, approach, commercial). The regression approach is used and is directly extended to multivariable analysis. Results are generated by the same method jointly stratifying by year and alternative factors to examine for interactions with year.

Calculations were performed using R 3.4.2's glm() with packages brglm and brglm2 to implement Firth's correction and to compute penalized deviances. Package profileModel profiled likelihoods. Package lsmeans performed asymptotic tests on pairwise differences. We attempted to use package logbin for log-link binomial GLMs; however, it did not converge in several calculations. Package rstanarm was used hierarchical regression by mcmc.

\section{SUPPLEMENTAL RESULTS \\ Secular Trend Analysis}

A Poisson GLM with a secular trend, common mean, and no other factors yielded a per-year risk ratio of 0.94 (95\% CI, 0.76-1.2; $P=.650$ vs common mean only). Attempting to account in-per year variation with a negative binomial model yielded identical conclusion (zero estimated overdispersion). The hierarchical linear model produced essentially identical results (relative risk [RR], 0.96; 95\% CI, 0.75-1.3).

Based on inspection of the doubly stratified plots of O:E ratio by year and risk factor (Appendix Figure 1), 
APPENDIX TABLE 2. Pairwise differences between each group by risk factor

\begin{tabular}{|c|c|c|c|c|c|}
\hline Year A & Year B & O:E/O:E & LB & UB & LRT-p \\
\hline 2008 & 2009 & 10 & 0.12 & 100 & 0.325 \\
\hline 2008 & 2010 & 10 & 0.18 & 100 & 0.331 \\
\hline 2008 & 2011 & 10 & 0.11 & 100 & 0.435 \\
\hline 2008 & 2012 & 10 & 0.37 & 100 & 0.215 \\
\hline 2008 & 2013 & 10 & 0.2 & 100 & 0.356 \\
\hline 2008 & 2014 & 10 & 0.19 & 100 & 0.364 \\
\hline 2008 & 2015 & 10 & 0.12 & 100 & 0.459 \\
\hline 2009 & 2010 & 0.82 & 0.08 & 17.62 & 0.872 \\
\hline 2009 & 2011 & 0.5 & 0.05 & 10.75 & 0.589 \\
\hline 2009 & 2012 & 1.3 & 0.19 & 25.39 & 0.81 \\
\hline 2009 & 2013 & 0.68 & 0.1 & 13.31 & 0.741 \\
\hline 2009 & 2014 & 0.66 & 0.1 & 12.84 & 0.719 \\
\hline 2009 & 2015 & 0.43 & 0.06 & 8.77 & 0.503 \\
\hline 2010 & 2011 & 0.61 & 0.07 & 5.08 & 0.623 \\
\hline 2010 & 2012 & 1.59 & 0.31 & 11.43 & 0.587 \\
\hline 2010 & 2013 & 0.83 & 0.16 & 5.99 & 0.832 \\
\hline 2010 & 2014 & 0.8 & 0.16 & 5.78 & 0.801 \\
\hline 2010 & 2015 & 0.53 & 0.09 & 4.02 & 0.498 \\
\hline 2011 & 2012 & 2.6 & 0.51 & 18.73 & 0.253 \\
\hline 2011 & 2013 & 1.36 & 0.27 & 9.82 & 0.717 \\
\hline 2011 & 2014 & 1.31 & 0.26 & 9.47 & 0.75 \\
\hline 2011 & 2015 & 0.87 & 0.14 & 6.59 & 0.877 \\
\hline 2012 & 2013 & 0.52 & 0.12 & 2.22 & 0.365 \\
\hline 2012 & 2014 & 0.51 & 0.12 & 2.14 & 0.339 \\
\hline 2012 & 2015 & 0.33 & 0.07 & 1.52 & 0.151 \\
\hline 2013 & 2014 & 0.96 & 0.23 & 4.08 & 0.959 \\
\hline 2013 & 2015 & 0.64 & 0.13 & 2.89 & 0.553 \\
\hline 2014 & 2015 & 0.66 & 0.13 & 3 & 0.585 \\
\hline Access A & Access B & O:E/O:E & LB & UB & LRT-p \\
\hline $\mathrm{TF}$ & TA & 3.46 & 1.23 & 11.12 & 0.018 \\
\hline $\mathrm{TF}$ & $\mathrm{TA}_{\mathrm{o}}$ & 1.82 & 0.51 & 6.56 & 0.346 \\
\hline TA & $\mathrm{TA}_{\mathrm{o}}$ & 0.53 & 0.16 & 1.48 & 0.229 \\
\hline Risk Group A & Risk Group B & O:E/O:E & LB & UB & LRT-p \\
\hline Low & Med & 10 & 0.22 & 100 & 0.319 \\
\hline Low & High & 10 & 0.37 & 100 & 0.239 \\
\hline Med & High & 1.29 & 0.43 & 5.51 & 0.678 \\
\hline Group 1 & Group 2 & O:E/O:E & LB & UB & LRT-p \\
\hline Research & Comm & 1.54 & 0.64 & 3.94 & 0.337 \\
\hline
\end{tabular}

Presented ratios were bounded below at 0.1 and above at 10. O:E, Observed-to-expected 30-day mortality; $L B$, lower boundary; $U B$, upper boundary; $L R T-p, P$ value of LRT versus 2 levels having the same O:E ratio; $T F$, transfemoral; $T A$, transapical; $T A_{o}$, transaortic; Comm, commercial inplant.

the only suggestion of a temporal trend occurred when stratifying by year and commercial versus research implant. As such, we tested for a trend adjusting for commercial versus research and optionally eliminating the initial year (2008). Adjusting minimally changed the result (RR, 0.9; 95\% CI, 0.71-1.14), but dropping 2008 created a nearly significant slope for the trend (RR, 0.73; 95\% CI, 0.51-1.03; $P=.066$ ). The hierarchical model reached similar conclusions (RR, 0.82; 95\% CI, 0.57-1.16). 


\section{Sensitivity Analysis for Choice of Analytic Method}

Point estimates of O:E ratios follow a few simple trends (Appendix Figure 2). First, the choice of a Poisson or binomial likelihood made little difference. Second, the results from the hierarchical regression model strongly shrink the year-by-year estimates to a common mean. Third, the Firth bias reduction correction shrinks all estimates toward an O:E ratio of 1 (the null model), with the difference meaningfully large only in 2008 (when there were zero mortality events). Otherwise, the Firth and uncorrected models closely track one another. Fourth, there was almost no difference between the individual-level and collapsed models.

The confidence intervals generated by the various methods by year are plotted in Appendix Figure 3. The bounds have been truncated between 0.1 and 10 for display purposes. The Firth bias reduction correction pulls confidence intervals toward 1 in a similar way as the point estimates, and is slightly wider in some cases, except those with few data. Poisson and binomial results are similar with Poisson intervals slightly farther from 1 and slightly wider. Hierarchical models again produce much smaller intervals for the years with little data by virtue of shrinkage.

Lastly, O:E ratios computed by maximum likelihood of collapsed Poisson likelihood with likelihood ratio-based CI were calculated for all subgroups (Appendix Table 1). To compare O:E ratios between subgroups, the ratios derived from optimization of the profile Poisson likelihood are divided by each other. $P$ value of likelihood ratio test versus two levels having the same O:E ratio are then generated (Appendix Table 2). Equivalently, this is the exponentiated difference in $\backslash$ beta parameters. 


\section{Adult: Aortic Valve}

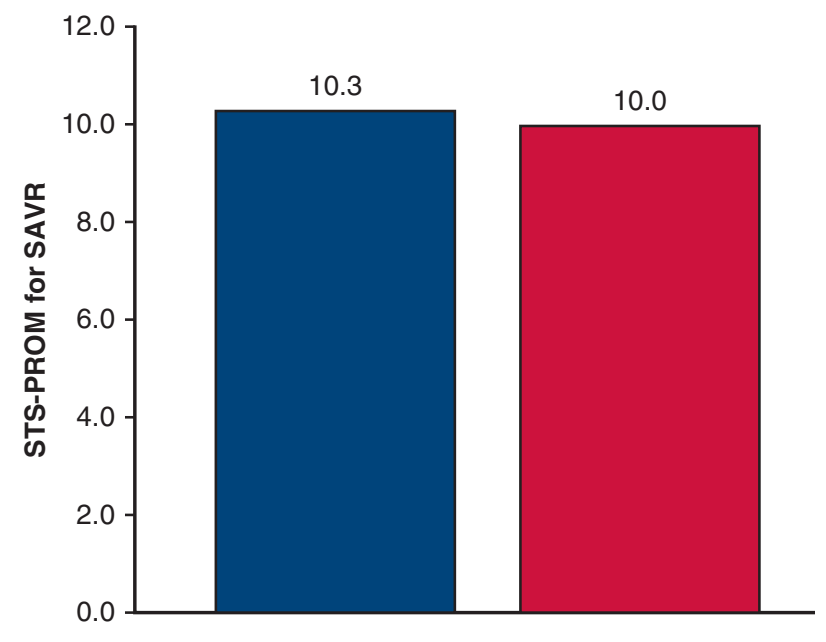

Original STS-PROM for SAVR (Version 2.61 or 2.73)

Recalculated STS-PROM for SAVR (v2.81)

FIGURE E1. Original Society for Thoracic Surgery Predicted Risk of Mortality (STS-PROM) for surgical aortic valve replacement (SAVR; versions 2.61 and 2.73) versus recalculated STS-PROM for SAVR (version 2.81). There was no significant difference between the original scores and the recalculated scores $(10.3 \pm 5.9$ vs $10.0 \pm 5.6 ; P=.69)$.

TABLE E1. Calculated O:E ratios for U.S. TAVR trials and Transcatheter Valve Therapeutics Registry

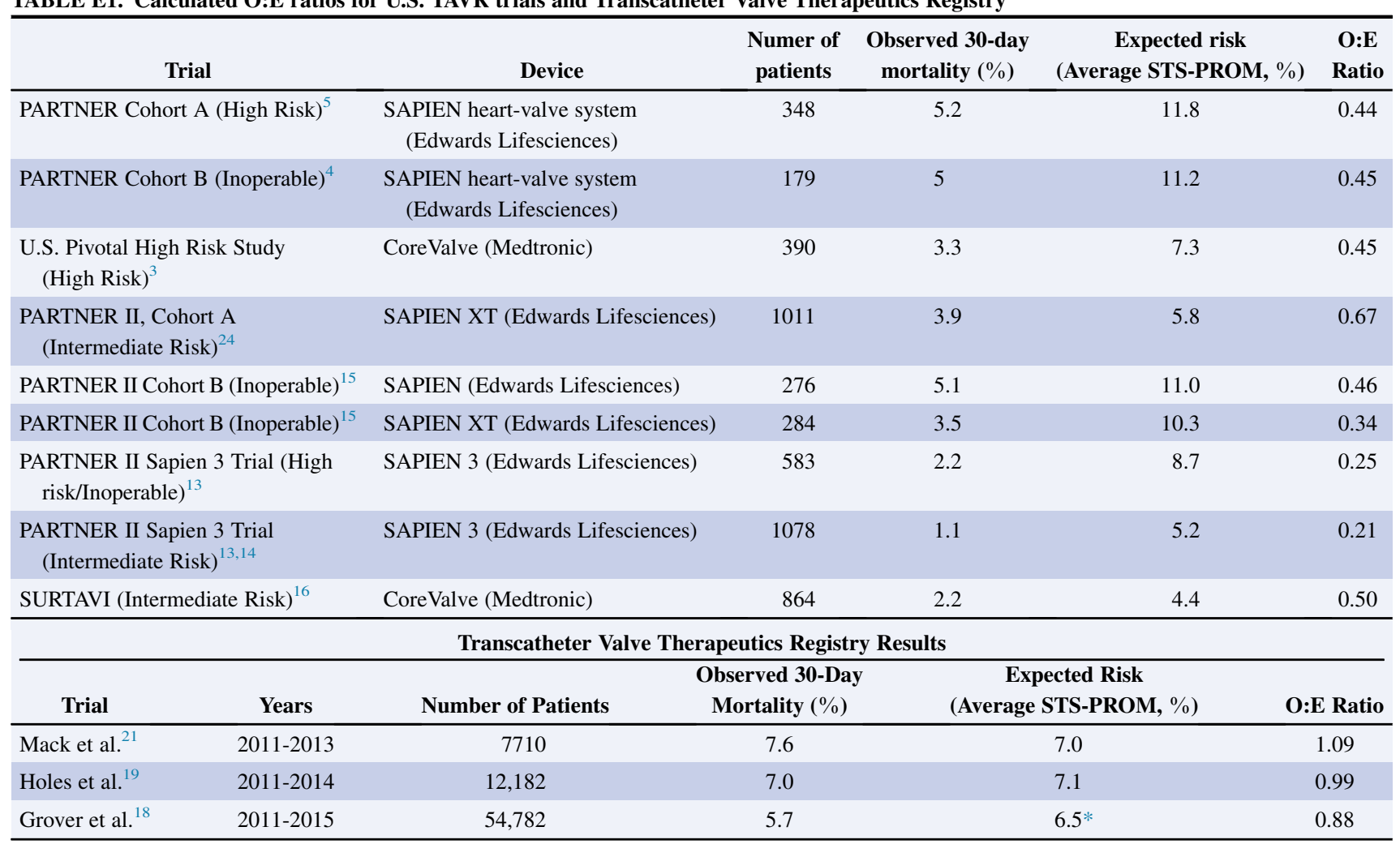

STS-PROM, Society for Thoracic Surgery Predicted Risk of Mortality; O:E ratio, observed-to-expected 30-day mortality ratio. *Median Society for Thoracic Surgery Predicted Risk of Mortality (STS-PROM). 
TABLE E2. Demographics

\begin{tabular}{|c|c|c|c|c|c|c|c|c|c|}
\hline Variable & $\begin{array}{c}2008 \\
(n=13)\end{array}$ & $\begin{array}{c}2009 \\
(n=11)\end{array}$ & $\begin{array}{c}2010 \\
(n=34)\end{array}$ & $\begin{array}{c}2011 \\
(n=54)\end{array}$ & $\begin{array}{c}2012 \\
(n=83)\end{array}$ & $\begin{array}{c}2013 \\
(n=91)\end{array}$ & $\begin{array}{c}2014 \\
(n=114)\end{array}$ & $\begin{array}{c}2015 \\
(n=146)\end{array}$ & $\begin{array}{c}P \\
\text { value }\end{array}$ \\
\hline Female sex & $7(54 \%)$ & $6(55 \%)$ & $18(53 \%)$ & $34(63 \%)$ & $34(41 \%)$ & $46(51 \%)$ & $50(44 \%)$ & $67(46 \%)$ & .293 \\
\hline Age (years) & $81.1 \pm 7.4$ & $80.2 \pm 6.6$ & $84.2 \pm 7.3$ & $85.4 \pm 6.6$ & $78.6 \pm 9.9$ & $79.8 \pm 9.3$ & $81.3 \pm 8.9$ & $80.6 \pm 9.0$ & .001 \\
\hline White race & $13(100 \%)$ & $11(100 \%)$ & $33(97 \%)$ & $53(98 \%)$ & $81(98 \%)$ & $85(93 \%)$ & $106(93 \%)$ & $137(94 \%)$ & .563 \\
\hline STS risk score, $\%$ & $9.2 \pm 3.6$ & $14.6 \pm 6.0$ & $11.5 \pm 5.1$ & $11.9 \pm 4.8$ & $8.0 \pm 4.7$ & $10.4 \pm 5.7$ & $8.7 \pm 4.3$ & $7.8 \pm 5.2$ & $<.0001$ \\
\hline $\begin{array}{l}\text { Premature family } \\
\text { history of CAD }\end{array}$ & $2(15 \%)$ & $1(9 \%)$ & $3(9 \%)$ & $9(17 \%)$ & $20(24 \%)$ & $9(10 \%)$ & $6(5 \%)$ & $13(9 \%)$ & .005 \\
\hline $\begin{array}{l}\text { Current or former } \\
\text { smoker }\end{array}$ & 0 & 0 & 0 & $2(4 \%)$ & $6(7 \%)$ & $7(7 \%)$ & $36(32 \%)$ & $91(62 \%)$ & $<.0001$ \\
\hline $\begin{array}{l}\text { Prior myocardial } \\
\text { infarction }\end{array}$ & $7(54 \%)$ & $5(46 \%)$ & $8(24 \%)$ & $18(33 \%)$ & $32(39 \%)$ & $42(46 \%)$ & $53(47 \%)$ & $30(27 \%)$ & .008 \\
\hline Diabetes & $6(46 \%)$ & $6(55 \%)$ & $15(44 \%)$ & $14(26 \%)$ & $27(33 \%)$ & $45(50 \%)$ & $55(48 \%)$ & $58(40 \%)$ & .054 \\
\hline Creatinine (mean) & $1.06 \pm 0.58$ & $1.39 \pm 0.38$ & $1.29 \pm 0.46$ & $1.12 \pm 0.36$ & $1.12 \pm 0.62$ & $1.32 \pm 0.93$ & $1.43 \pm 1.28$ & $1.29 \pm 0.73$ & .215 \\
\hline Creatinine (median) & $1.0(0.5-2.8)$ & $1.4(0.7-2.0)$ & $1.25(0.6-3.0)$ & $1.1(0.4-2.2)$ & $1.0(0.53-5.9)$ & $1.12(0.3-7.7)$ & $1.1(0.6-10.2)$ & $1.1(0.3-5.5)$ & .059 \\
\hline Renal failure & $1(8 \%)$ & $1(9 \%)$ & $2(6 \%)$ & $2(4 \%)$ & $5(6 \%)$ & $12(13 \%)$ & $9(8 \%)$ & $22(15 \%)$ & .166 \\
\hline HTN & $9(69 \%)$ & $9(82 \%)$ & $28(82 \%)$ & $49(91 \%)$ & $80(96 \%)$ & $89(98 \%)$ & $111(97 \%)$ & $137(94 \%)$ & $<.0001$ \\
\hline Dyslipidemia & $11(85 \%)$ & $10(91 \%)$ & $29(86 \%)$ & $42(78 \%)$ & $79(95 \%)$ & $88(97 \%)$ & $103(90 \%)$ & $129(88 \%)$ & .014 \\
\hline Immunocompromised & $1(8 \%)$ & $1(9 \%)$ & $5(15 \%)$ & $6(11 \%)$ & $10(12 \%)$ & $12(13 \%)$ & $11(10 \%)$ & $11(8 \%)$ & .869 \\
\hline PVD & $3(23 \%)$ & $5(46 \%)$ & $14(41 \%)$ & $37(69 \%)$ & $55(66 \%)$ & $53(58 \%)$ & $56(49 \%)$ & $45(31 \%)$ & $<.0001$ \\
\hline CVD & $3(23 \%)$ & $1(9 \%)$ & $16(47 \%)$ & $15(28 \%)$ & $21(25 \%)$ & $27(30 \%)$ & $32(28 \%)$ & $72(49 \%)$ & $<.0001$ \\
\hline COPD & $3(23 \%)$ & $6(55 \%)$ & $20(59 \%)$ & $31(57 \%)$ & $50(60 \%)$ & $58(64 \%)$ & $60(53 \%)$ & $80(55 \%)$ & .232 \\
\hline NYHA grade & & & & & & & & & .141 \\
\hline I & 0 & 0 & 0 & 0 & 0 & 0 & $1(1 \%)$ & 0 & \\
\hline II & 0 & 0 & $2(6 \%)$ & $2(4 \%)$ & $4(5 \%)$ & $4(4 \%)$ & $7(6 \%)$ & $11(8 \%)$ & \\
\hline III & $7(54 \%)$ & $3(27 \%)$ & $20(59 \%)$ & $33(61 \%)$ & $57(69 \%)$ & $48(53 \%)$ & $73(64 \%)$ & $102(70 \%)$ & \\
\hline IV & $6(46 \%)$ & $8(73 \%)$ & $12(35 \%)$ & $19(35 \%)$ & $22(27 \%)$ & $39(43 \%)$ & $33(29 \%)$ & $33(23 \%)$ & \\
\hline Mean AV gradient & $41.3 \pm 10.4$ & $42.2 \pm 16.3$ & $43.2 \pm 11.9$ & $45.1 \pm 13.8$ & $42.2 \pm 13.2$ & $42.1 \pm 13.4$ & $42.3 \pm 11.9$ & $41.9 \pm 14.6$ & .931 \\
\hline $\mathrm{EF}, \%$ & $50.9 \pm 18.7$ & $48.3 \pm 15.7$ & $53.3 \pm 12.7$ & $51.8 \pm 16.0$ & $52.8 \pm 15.0$ & $53.1 \pm 15.3$ & $54.3 \pm 14.3$ & $57.0 \pm 15.0$ & .194 \\
\hline
\end{tabular}

STS, Society for Thoracic Surgery; CAD, coronary artery disease; $H T N$, hypertension; $P V D$, pulmonary vascular disease; $C V D$, cardiovascular disease; COPD, chronic obstructive pulmonary disease; $N Y H A$, New York Heart Association; $A V$, aortic valve; $E F$, ejection fraction. 
TABLE E3. Perioperative Results

\begin{tabular}{|c|c|c|c|c|c|c|c|c|c|}
\hline Variable & $\begin{array}{c}2008 \\
(n=13)\end{array}$ & $\begin{array}{c}2009 \\
(n=11)\end{array}$ & $\begin{array}{c}2010 \\
(n=34)\end{array}$ & $\begin{array}{c}2011 \\
(n=54)\end{array}$ & $\begin{array}{c}2012 \\
(n=83)\end{array}$ & $\begin{array}{c}2013 \\
(n=91)\end{array}$ & $\begin{array}{c}2014 \\
(n=114)\end{array}$ & $\begin{array}{c}2015 \\
(n=146)\end{array}$ & $\begin{array}{c}P \\
\text { value }\end{array}$ \\
\hline ICU readmission & 0 & $1(9 \%)$ & $1(3 \%)$ & $2(4 \%)$ & $4(5 \%)$ & $4(4 \%)$ & $4(4 \%)$ & $2(2 \%)$ & .976 \\
\hline Reintubation & 0 & $1(9 \%)$ & 0 & $2(4 \%)$ & $2(2 \%)$ & $5(6 \%)$ & $3(3 \%)$ & $1(2 \%)$ & .639 \\
\hline Any complication & $5(39 \%)$ & $7(64 \%)$ & $15(44 \%)$ & $14(26 \%)$ & $23(28 \%)$ & $35(39 \%)$ & $54(47 \%)$ & $62(43 \%)$ & .030 \\
\hline CVA & $1(8 \%)$ & 0 & $1(3 \%)$ & 0 & $3(4 \%)$ & 0 & $1(1 \%)$ & $2(1 \%)$ & .234 \\
\hline TIA & 0 & 0 & 0 & 0 & $1(1 \%)$ & $1(1 \%)$ & 0 & 0 & .744 \\
\hline Renal failure & 0 & $1(9 \%)$ & $1(3 \%)$ & $1(2 \%)$ & 0 & $2(2 \%)$ & 0 & 0 & .035 \\
\hline Pacemaker & 0 & 0 & 0 & $3(6 \%)$ & $3(4 \%)$ & $5(6 \%)$ & $11(10 \%)$ & $19(13 \%)$ & .043 \\
\hline Atrial fibrillation & $1(8 \%)$ & $1(9 \%)$ & $7(21 \%)$ & $6(11 \%)$ & $12(15 \%)$ & $9(10 \%)$ & $19(17 \%)$ & $18(12 \%)$ & .715 \\
\hline Mean LOS, d & $4.0 \pm 1.5$ & $9.9 \pm 9.0$ & $7.2 \pm 5.6$ & $6.4 \pm 3.6$ & $6.9 \pm 6.8$ & $6.9 \pm 4.0$ & $6.9 \pm 4.1$ & $6.8 \pm 7.0$ & .425 \\
\hline Median LOS, d (range) & $4(2-7)$ & $7(2-35)$ & $5(0-29)$ & $5(3-21)$ & $5(0-61)$ & $6(1-25)$ & $6(2-26)$ & $5(0-58)$ & .097 \\
\hline Operative mortality & 0 & $1(9 \%)$ & $2(6 \%)$ & $2(4 \%)$ & $6(7 \%)$ & $4(4 \%)$ & $4(4 \%)$ & $3(2 \%)$ & .615 \\
\hline $\begin{array}{l}\text { Readmission at } 30 \mathrm{~d} \text { from } \\
\text { index DC }\end{array}$ & 0 & $3(27 \%)$ & 0 & $6(11 \%)$ & $6(7 \%)$ & $8(9 \%)$ & $13(11 \%)$ & $13(9 \%)$ & .158 \\
\hline
\end{tabular}

$\overline{I C U}$, Intensive care unit; $C V A$, cerebrovascular accident; TIA, transient ischemic attack; $L O S$, length of stay; $D C$, discharge. 